\title{
Erratum to: EUS-guided gastroenterostomy is comparable to enteral stenting with fewer re-interventions in malignant gastric outlet obstruction
}

Yen-I Chen ${ }^{1}$ (D) Takao Itoi ${ }^{2} \cdot$ Todd H. Baron $^{3} \cdot$ Jose Nieto $^{4} \cdot$ Yamile Haito-Chavez $^{1}$ • Ian S. Grimm ${ }^{3}$ - Amr Ismail ${ }^{1}$ - Saowanee Ngamruengphong ${ }^{1}$ - Majidah Bukhari ${ }^{1}$. Gulara Hajiyeva $^{1} \cdot$ Ahmad S. Alawad $^{1} \cdot$ Vivek Kumbhari $^{1} \cdot$ Mouen A. Khashab $^{1}$

Published online: 17 July 2017

(C) Springer Science+Business Media, LLC 2017

Erratum to: Surg Endosc (2017) 31(7): 2946-2952

DOI 10.1007/s00464-016-5311-1

The correct Family Name of the eighth author is "Ngamruengphong".

The online version of the original article can be found under doi:10.1007/s00464-016-5311-1.

Takao Itoi

itoi@tokyo-med.ac.jp

1 Division of Gastroenterology and Hepatology, Johns Hopkins Medical Institutions, Baltimore, MD, USA

2 Division of Gastroenterology and Hepatology, Tokyo Medical University, Shinjuku-ku, Tokyo, Japan

3 Division of Gastroenterology and Hepatology, University of North Carolina, Chapel Hill, NC, USA

4 Borland-Groover Clinic, Jacksonville, FL, USA 